\title{
Protocolos de ensaios clínicos: relevância e contribuições além da qualidade metodológica
}

\author{
Clinical trial protocols: relevance and \\ contributions beyond methodological quality
}

\section{Fuad Ahmad Hazime ${ }^{1}$ Vinicius Saura Cardoso ${ }^{2}$ (D)}

${ }^{1}$ Autor para correspondência. Universidade Federal do Delta do Parnaíba (Parnaíba). Piauí, Brasil. fuad@ufpi.edu.br universidade Federal do Delta do Parnaíba (Parnaíba). Piauí, Brasil. vscfisio@ufpi.edu.br

A crise sanitária mundial decorrente da pandemia do novo coronavírus tem demonstrado a extrema importância das pesquisas clínicas de intervenção (ensaios clínicos) e, principalmente, a necessidade do rigor metodológico na condução dos protocolos e interpretação de seus resultados. No entanto, quando há restrição de acesso e conhecimento detalhado de protocolos clínicos, os graus de incerteza sobre segurança e eficácia de uma terapia aumentam consideravelmente.

Neste contexto, o registro e a publicação prévios de protocolos de ensaios clínicos permitem a comparação entre o que foi planejado e executado pelos pesquisadores. 1 O processo de registro é de fácil execução e pode ser realizado em plataformas virtuais de livre acesso internacionais, como, por exemplo, o Americano https://clinicaltrials.gov ou o Brasileiro https://ensaiosclinicos. gov.br. O registro de protocolos de ensaios clínicos apresenta muitas vantagens: (1) publicidade e transparência sobre pesquisas em andamento; (2) fidelidade aos preceitos éticos e às boas práticas de pesquisa clínica; (3) contribuições para o estado da arte e mudanças na tomada de decisão clínica; e (4) evitar duplicidades e dispêndio desnecessários de recursos.

Considerando os potenciais benefícios acima, algumas revistas científicas começaram a exigir 0 registro de protocolos clínicos como pré-requisito para submissão de manuscritos e posterior publicação. ${ }^{23}$ No entanto, apesar desta importante iniciativa, ainda há falhas na aderência dos artigos publicados em relação aos seus respectivos registros, principalmente no relatório seletivo de desfechos clínicos.., 5

Atualmente, há um grande interesse de pesquisadores pela publicação de protocolos de ensaios clínicos tanto em periódicos internacionais quanto nacionais. A publicação prévia destes protocolos ou propostas de estudos clínicos contribuem para que a comunidade científica, profissionais de saúde, pacientes, agências de fomento e de políticas públicas de saúde possam se atualizar sobre novas pesquisas clínicas em andamento e acompanhar os resultados futuros. 
Há também benefícios aos próprios autores: (1) promoção do grupo ou centro de pesquisa; (2) chamar a atenção de outros grupos de pesquisa para novas parcerias; (3) possibilidade de autoria e contribuição intelectual para o "estado da arte" e (4) aumento do número de publicações e escores acadêmicos.

Embora as contribuições e benefícios apontados acima sejam necessários e legítimos, a publicação de protocolos de pesquisa clínica deveria contribuir além dos aspectos de transparência e qualidade metodológica. A real contribuição para o estado da arte - ou maior nível de conhecimento/desenvolvimento sobre determinado tema/campo de pesquisa - provém de um protocolo cujo racional teórico-científico explora novas possibilidades e apresenta argumentos plausíveis.

Neste sentido, protocolos que apresentam uma extensão de seu (prévio) registro em formato de artigo científico trazem consigo um conteúdo com pouca contribuição para a comunidade científica e o progresso da ciência. A submissão de protocolos para publicação é uma oportunidade para os autores demonstrarem a relevância do seu estudo, ou seja, porque seus resultados podem trazer importantes informações para guiar o futuro uso (ou não) de uma determinada terapia. Mais ainda, porque esta proposta de pesquisa diminuirá os graus de incerteza sobre a sua eficácia terapêutica.

Protocolos perfeitos, isentos de vieses e que tragam uma resposta final e decisiva são utópicos e incompatíveis com a experimentação humana. Entretanto, estes aspectos podem ser melhor explorados na tentativa de diminuir as fragilidades de uma proposta terapêutica e os graus de incerteza sobre a sua relevância e potencial aplicabilidade.

Outra importante questão, ainda pouco abordada nos protocolos, é a excessiva valorização da significância estatística em detrimento da significância clínica. Uma diferença estatisticamente significativa ou $\mathrm{p}<0,05$, por exemplo, pode ser interpretada da seguinte forma: "meus resultados encontrados têm uma probabilidade menor do que $5 \%$ de terem ocorrido ao acaso". Este é um passo importante na descrição dos resultados, no entanto, não significa que uma terapia seja clinicamente eficaz.
É preciso demonstrar a magnitude do efeito encontrado. 6.7 Por exemplo, uma terapia para o tratamento de condições de dor crônica pode apresentar um resultado estatisticamente significativo para o alívio da dor, em comparação a um tratamento placebo. No entanto, uma redução da intensidade de dor (Escala Numérica de 11 pontos) menor do que 2 pontos não é considerada uma diferença clínica minimamente importante. $\mathrm{A}$ informação de que os desfechos primários e secundários serão interpretados considerando-se seus escores de significância clínica traz mais transparência e confiabilidade ao leitor. E algumas revistas já estão solicitando isso aos autores. ${ }^{9}$

Precisamos avançar rapidamente na incorporação de informações que realmente tragam contribuições relevantes para o progresso da ciência, pois outros aspectos também deverão ser abordados nos protocolos clínicos: os custos e as consequências de uma intervenção em saúde.

\section{Conflitos de interesses}

Nenhum conflito financeiro, legal ou político envolvendo terceiros (governo, empresas e fundações privadas, etc.) foi declarado para nenhum aspecto do trabalho submetido (incluindo, mas não se limitando a subvenções e financiamentos, participação em conselho consultivo, desenho de estudo, preparação de manuscrito, análise estatística, etc.).

\section{Referências}

1. Chan AW, Hrobjartsson A. Promoting public access to clinical trial protocols: challenges and recommendations. Trials. 2018;19(1):116. https://doi.org/10.1186/s13063-018-2510-1

2. De Angelis C, Drazen JM, Frizelle FA, Haug C, Hoey J, Horton R, et al. Clinical trial registration: a statement from the International Committee of Medical Journal Editors. Lancet. 2004;364(9438):911-2. https://doi.org/10.1016/s01406736(04)17034-7

3. De Angelis CD, Drazen JM, Frizelle FA, Haug C, Hoey J, Horton $\mathrm{R}$, et al. Is this clinical trial fully registered? A statement from the International Committee of Medical Journal Editors. N Engl J Med. 2005;352(23):2436-8. https://doi.org/10.1056/nejme058127

4. Mathieu S, Boutron I, Moher D, Altman DG, Ravaud P. Comparison of registered and published primary outcomes in randomized controlled trials. JAMA. 2009;302(9):977-84. https:// doi.org/10.1001/jama.2009.1242 
5. Sendyk DI, Souza NV, César Neto JB, Tatakis DN, Pannuti $\mathrm{CM}$. Selective outcome reporting in root coverage randomized clinical trials. J Clin Periodontol. 2021;48(6):867-77. https://doi. org/10.1111/jcpe.13451

6. Currey JD, Baxter PD, Pitchford JW. Significance and importance: some common misapprehensions about statistics. Cell Biochem Funct. 2009;27(8):499-502. https://doi.org/10.1002/cbf.1620

7. Sullivan GM, Feinn R. Using Effect Size-or Why the P Value Is Not Enough. J Grad Med Educ. 2012;4(3):279-82. https://dx.doi. org/10.4300\%2FJGME-D-12-00156.1
8. Dworkin RH, Turk DC, Wyrwich KW, Beaton D, Cleeland $\mathrm{CS}$, Farrar JT. Interpreting the clinical importance of treatment outcomes in chronic pain clinical trials: IMMPACT recommendations. J Pain. 2008;9(2):105-21. https://doi. org/10.1016/j.jpain.2007.09.005

9. Cavalcante PGL, Baptista AF, Cardoso VS, Filgueiras MC, Hasue $\mathrm{RH}$, João SMA, et al. Transcranial Direct Current Stimulation Combined With Therapeutic Exercise in Chronic Low Back Pain: Protocol of a Randomized Controlled Trial. Phys Ther, 2020;100(9):1595-602. https://doi.org/10.1093/ptj/pzaa105 